add to our meagre knowledge of his life and character and of the friends among whom he worked. He would, I feel sure, have been particularly gratified by Dr. Robert Hutchison's clear demonstration that he was endowed with the priceless gift of a sense of humour.

He would have noted with surprise that the Presidential chair is occupied this afternoon for the seventh year in succession by the same Fellow, an event with only a single precedent since Sir Henry Halford ruled over the College for the twenty-four years between 1820 and 1844 . He would realize that this could only be the result of the immense satisfaction of the Fellows for the manner in which its affairs have been conducted by Lord Dawson, during whose tenure of office the influence of the College on medical education, medical research, and the public health has become more profound and more far-reaching than ever before.

Harvey would be pleased to see how well his admonitions have been remembered, and to find that after three hundred years Fellows and members of the College are still taking a leading part in " the research and study of the secrets of Nature by way of experiment." And at the end of each Oration he would retire to the Elysian Fields, happy in the knowledge that "to the honour of the profession" the Fellows of the College "continue to live in mutual love and affection amongst themselves."

\section{ABSCESS OF LUNG *}

BY

\section{S. T. BURRELL, M.D., F.R.C.P.}

Physician to the Royal Free Hospital and to the Brompton Hospital for Consumption and Diseases of the Chest

An abscess may be defined as a collection of pus in any part of the body. In the lung it may be single or multiple and result from a variety of causes. Strictly speaking, tuberculous or bronchiectatic cavities are abscesses. Pyaemia resulting from osteomyelitis or operation often leads to multiple abscesses. Maxwell (1934) found that in a series of 116 cases of multiple abscess sixty-two followed septic conditions elsewhere. Of 199 cases of single pulmonary abscess forty-three resulted from pneumonia, thirty-two were associated with bronchial carcinoma, twenty-three with septic foci in some distant part of the body, and only two followed tonsillectomy. A considerable proportion of single lung abscesses which I have seen followed tonsillectomy or some other operation on the throat, nose, or teeth. Scott Pinchin and Morlock (1930) found tonsillectomy responsible for 16 per cent. of their cases. There is also a number of cases for which no cause can be discovered. In this paper cases of multiple abscess or those associated with tuberculosis, carcinoma, or other gross disease are not considered, and I shall confine my remarks to the single abscess such as occurs for no apparent reason or as a result of pneumonia, ruptured empyema, embolism, or aspiration.

\section{Diagnosis}

The first symptoms are a feeling of malaise and sometimes a nasty taste in the mouth. The breath is often offensive even before there is any sputum. Onset may be with haemoptysis, but this is more common in cases associated with carcinoma. The temperature is usually raised, and if there is not free drainage through a bronchus

* Read in opening a discussion at a joint meeting of the Section of Medicine and Surgery at the Annual Meeting of the British Medical Association, Belfast, 1937. it may be hectic in character. Clubbing of the fingers appears early. If there is sputum it may contain elastic fibres and pyogenic organisms, and is not usually offensive unless there is gangrene, which - is said to be due to the Miller-Vincent spirochaetes present in the gums of many normal adults.

On examination there may be no physical signs if the abscess is deeply situated. If superficial there may be dullness or signs of associated pleurisy. Radiography shows a shadow which may contain a fluid level. It may, however, show merely an area of opacity which closely resembles a neoplasm or simple inflammatory lesion. If neohydriol is injected into the trachea it does not as a rule enter the abscess cavity.

It is best to locate the abscess by $x$-ray.films taken in different positions-antero-posterior, oblique, and lateral. Stereoscopic radiographs are apt to be misleading. It has been said that an exploring needle should not be used to locate an abscess, since it may lead to infection of the pleural cavity and of the lung along the track of the needle. I agree that it is unnecessary to aspirate a lung abscess, but think the danger of the procedure causing infection is much exaggerated, and I have never known it happen.

\section{Prognosis}

Abscess of lung must always be regarded as a very serious condition, whatever line of treatment is adopted. Death may occur from extension into the lung tissue, toxaemia, haemoptysis, or embolic spread to some distant part, usually the brain. Cerebral abscess appears to bo rather more common in cases treated surgically.

\section{Treatment}

Most authorities agree that medical treatment should be given a good trial in cases of single pulmonary abscess. Postural drainage is often sufficient to enable the patient to cough up the abscess and make a good recovery. An abscess in the upper zone is best drained with the patient sitting well propped up, and he should lie on his back for an abscess in the front part of the lung and on his face for one situated posteriorly. In the case of an abscess in the lower zone he should lie on a bed with the pelvis raised and the chest and head sloping downwards. For this purpose a bed such as that devised by $\mathrm{Mr}$. Nelson is of great value. This can be raised in the middle so that the patient can drain for a long time, and although the position looks uncomfortable it is remarkable how quickly a patient gets used to it. By this means a number of cases can be cured, and it is wise to allow a full six weeks before surgical treatment is attempted. If patients are acutely ill with a large amount of sputum postural drainage is not advisable, and it is usually best to operate.

Treatment by artificial pneumothorax is now rarely employed, chiefly owing to the fear of the abscess rupturing into the pleural cavity and producing a pyothorax. There is a very definite danger of this accident, but in a number of cases the patient has eventually recovered after draining the pleural cavity. It may happen that apart from pneumothorax the abscess breaks into the pleural cavity and very foul pus is found. These cases often do quite well with drainage. In the case of a deep abscess draining into a bronchus pneumothorax is still sometimes employed. In my opinion the chief danger of pneumothorax is (as is usually the case) that the pleura is adherent in the neighbourhood of the abscess and on cough a tear occurs at the junction where the lung is adherent to the chest wall and opens the abscess 
into the pleural cavity. If there are no adhesions artificial pneumothorax is not an unsafe method of treatment

In a series of eight cases of simple abscess which I treated by artificial pneumothorax four patients made a good recovery and are still well. In two the abscess ruptured into the pleural cavity, but both recovered after drainage and are now well; in one the symptoms persisted and thoracoplasty was later performed; and in one the patient died after an operation for dividing the adhesions. I think, however, that if postural treatment fails it is on the whole safer to employ surgical drainage.

Aspiration through a bronchoscope has been performed and several successful cases described. This really may be regarded as an additional method of draining the abscess cavity medically, and if used should be combined with postural drainage. In certain cases it may be wise to give this method a trial, although if the abscess persists operation should not be too long delayed.

Surgical treatment consists in opening the abscess and draining. The operation should be performed in two stages; the first is intended to produce adhesions between the chest wall and the pleura over the cavity, and the second to drain the abscess. There are definite dangers, and the operation should be regarded as a serious one. Haemorrhage may occur later; cerebral abscess is perhaps slightly more common after operation than in cases treated medically, or infection may spread throughout the lung. It would appear that as methods of postural drainage improve this will be the treatment of choice in cases of abscess.

Intravenous injections of alcohol have been suggested, and $10 \mathrm{c.cm}$. of a 20 per cent. solution is that most commonly used. Sodium benzoate has been recommended for treatment of gangrene and abscess of lung: the dose advocated here is $20 \mathrm{c} . \mathrm{cm}$. of a 20 per cent. solution, increased up to $50 \mathrm{c.cm}$., given daily. I have no experience of either of these methods.

In cases of gangrene good results have been recorded from an intensive course of treatment with arsphenamine, the object being to kill the spirochaetes which cause the gangrene. It is certain that some of the cases in which the sputum is most offensive do quite well on simple medical treatment, and I have not convinced myself that improvement has been due to the arsenic. As the spirochaetes are sometimes found in the gums of normal people pre-operative dental treatment has been advocated, and it is claimed that this reduces the pulmonary complications.

\section{REFERENCES}

Maxwell, J. (1934). Quart. J. Med., 26, 467.

Pinchin, A. J. Scott, and Morluck, H. V. (1930). Lancet, 2, 842.

A new German quarterly journal, Fortschritte der Erbpathologie Rassenhygiene und ihrer Grenzgebiete, has appeared; it is published by Georg Thieme of Leipzig. The joint editors are Dr. J. Schottky of Hildburghausen and Professor F. von Verschuer of Frankfurt-a-M. The first issue is dated July, 1937, and in addition to an introductory editorial explanatory note contains an article on the transmission of intelligence and character which is contributed by Dr. K. Gottschaldt of Berlin, another by Dr. Wülker of Berlin on the investigation of natural selection, and a third by Dr. H. Schade of Frankfurt on the biological aspects of heredity. As indicated by these opening articles, the new periodical should appeal particularly to those who are concerned with the influence of heredity, particularly on the pathological side, racial hygiene, and related topics. The annual subscription is 16 RM.

\section{A RAPID METHOD FOR ISOLATION OF ORGANIC POISONS PRELIMINARY NOTE BY}

\section{P. STEWART,* S. K. CHATTERJI AND}

\section{SYDNEY SMITH}

from the

Department of Forensic Medicine, University of Edinburgh

The standard method for the isolation of organic poisons from viscera, stomach contents, etc., is that described in the majority of medico-legal and toxicological textbooks as the Stas-Otto process. It is a slow, laborious, and often difficult method based on the repeated precipitation of proteins, fats, and similar interfering substances by alcohol, the organic poisons (alkaloids in the form of their salts) being retained in solution. Complete removal of the interfering substances involves repeated precipitation, each of which probably causes some loss of the substance sought. To minimize these losses thorough extraction of the precipitated material is required, and even with distillation in vacuo the evaporation of the relatively large volumes of alcohol (or aqueous alcohol in the early stages) is very time-consuming. On the other hand, if the Stas-Otto process is carefully carried out there is little likelihood of any of the commoner organic poisons, administered in lethal dose, being missed. It is not uncommon, for example, for morphine, given in medicinal doses, to be detected in the viscera post mortem.

It is obvious, however, that a shortening and simplification of the extraction process is very desirable, provided $j t$ can be achieved without any loss of power to detect very small amounts of poisonous substances. An alternative is supplied by Lloyd's process (Sydney Smith, 1936), which consists in preparing an acid-water-alcohol extract of the material as in the Stas-Otto process, and adsorbing any alkaloids present in this extract on fuller's earth. Adsorbents at this stage, however, are likely to take up many substances other than alkaloids, and, moreover, we have found fuller's earth to be notably inefficient in the adsorption of alkaloids.

Not only alkaloids, but most other poisons usually classed as organic, are of such a chemical nature that one would expect them to be adsorbed by various earths, though not all under the same conditions. Hence a hopeful line of attack seemed to be available for the isolation of the poisons once the proteins and fats have been removed, and the problem resolved itself into two parts-(a) to find a rapid and safe method of removing such interfering substances as protein, fat, etc., with minimal loss of the poisons to be sought; $(b)$ to find a suitable adsorbing agent and the conditions required for the adsorption and elution of the different types of poisons.

Since our first consideration was the detection of alkaloidal poisons we were concerned primarily with the possibility of adsorption from acid solution and with preliminary treatment which could be carried out completely at reactions below $p \mathrm{H} 7$.

\section{Precipitation by Trichloracetic Acid}

Of the various protein precipitants used in blood analysis some (like zinc hydroxide) function in an alkaline medium, others (like tungstic acid) involve little change in the reaction of the original material, and others again (like metaphosphoric acid or trichloracetic acid) are strongly * In receipt of a part-time grant from the Medical Research
Council. 